Journal of Animal and Veterinary Advances 11 (9): 1411-1419, 2012

ISSN: $1680-5593$

(C) Medwell Journals, 2012

\title{
Effect of n-3 Polyunsaturated Fatty Acids on Induction of Hypoxia Inducible Factor-2 Alpha in $\mathrm{C}_{2} \mathrm{C}_{12}$ Myotubes
}

\author{
Jize Zhang, Xiangshu Piao and Defa Li \\ National Key Laboratory of Animal Nutrition, College of Animal Science and Technology, \\ China Agricultural University, 100193 Beijing, People's Republic of China
}

\begin{abstract}
Results from different trails have provided evidence of protective effects of n-3 Polyunsaturated Fatty Acids (n-3 PUFAs) on heart and skeletal muscle. But the induction of Hypoxia Inducible Factors (HIFs) by n-3 PUFAs in these protective effects has never been reported before. The aim of this study was to find out if the marine n-3 fatty acids Eicosapentaenoic Acid (EPA) and Docosahexaenoic Acid (DHA) and of the plant-derived Alpha Linolenic Acid (ALA) and Stearidonic Acid (SDA) can induce HIFs in $\mathrm{C}_{2} \mathrm{C}_{12}$ myotubes and subsequent effect on cell metabolism. The n-3 PUFAs, especially DHA, EPA and SDA increased the levels of protein and mRNA in HIF-2 $\alpha$ at $72 \mathrm{~h}$. Meanwhile, n-3 PUFAs also elevated the expression of HIF related transcriptional factors like PDK 4 and PPAR $\alpha$ at $72 \mathrm{~h}$. The reprogramming of basal metabolism in $\mathrm{C}_{2} \mathrm{C}_{12}$ myotubes increased in GLUT4 and CPT1b gene expression by treatment of n-3 PUFAs at $72 \mathrm{~h}$. UCP 2 was increased by n-3 PUFAs for attenuating production of ROS at $72 \mathrm{~h}$. n-3 PUFAs, especially DHA, EPA and SDA could induce HIF-2 $\alpha$ which is associated with upregulation of $\operatorname{PDK} 4$ by activation of $\operatorname{PPAR} \alpha$. This process also implies a reprogramming of basal metabolism and oxidative damage protection in $\mathrm{C}_{2} \mathrm{C}_{12}$ myotubes.
\end{abstract}

Key words: $n-3$ PUFAs, HIF-2 $\alpha, \operatorname{PDK} 4, \operatorname{PPAR} \alpha$, basal metabolism, skeletal muscle

\section{INTRODUCTION}

Heart diseases like Coronary Heart Disease (CHD), Myocardial Infarction (MI) and myocardial ischemia are causing more and more deaths in recent decades all over the world because of the intake of high proportion energy and unbalanced dietary habits (Jalali-Khanabadi et al., 2006; Shekhar et al., 2006; Mazloom et al., 2008; Xu et al., 2010). So, a lot of research has been done for preventing these diseases by using variable chemicals (Granzotto et al., 2005; Jun et al., 2007; Anand et al., 2008; Ara et al., 2008; Nishimura et al., 2011; Liu et al., 2011).

Among these different chemicals, special attention has been paid to n-3 Polyunsaturated Fatty Acids (n-3 PUFAs) (Fang et al., 2011; Joensen et al., 2010). The n-3 PUFAs refer to a family of unsaturated fatty acids which mainly originate from the plant-derived n-3 fatty acids: Alpha Linolenic Acid (ALA; C18:3 n-3) and Stearidonic Acid (SDA; C18:4 n-3) or the marine n-3 fatty acids: Docosahexaenoic Acid (DHA; C22:6 n-3) and Eicosapentaenoic Acid (EPA; C20:5 n-3) (Mu, 2008; Ruiz-Lopez et al., 2009; Lorgeril de and Salen, 2004).

The mechanism of beneficial effects of n-3 PUFAs on cardiovascular diseases is mediated through different ways. In clinical experiments, the effect of n-3 PUFAs in patients is predominantly on antiatherogenic in lipid metabolism (Kris-Etherton et al., 2002; Vannice and Kelly, 2004; De Lorgeril et al., 1994). In animal models, besides changing lipid parameters in blood serum, dietary n-3 PUFAs supplementation can protect against myocardial resistance to ischemia-reperfusion injury (Ogita et al., 2003), reduce myocardial infarct sizes and arrhythmias (Xiao et al., 2008) or decrease $\mathrm{O}_{2}$ consumption and increase oxygen utilization efficiency (Pepe and McLennan, 2002).

The main explanations of n-3 PUFAs for reducing cardiac oxygen consumption and increasing the efficiency of cardiac metabolism are concentrated on the incorporation of n-3 PUFAs into myocardial membrane (Pepe and McLennan, 2002) and feeding related cellular calcium regulation (Singh et al., 2010). However, it was recently noted that cardiomyocytes can activate an endogenous oxygen-sensitive transcriptional programme when the myocardium is challenged by a low oxygen supply in areas of acute or chronic ischaemia. This process is mediated by Prolyl Hydroxylases (PHDs) which act as oxygen sensors to control the expression of Hypoxia-Inducible Factors (HIFs) (Bernhardt et al., 2007). $\mathrm{PHDs}$, present in three forms in mammalian cells are 2-oxoglutarate dioxygenases designated PHD1-PHD3

Corresponding Author: Defa Li, College of Animal Science and Technology, 2-Yuan-Ming-Yuan West Road, Haidian District, 100193 Beijing, China 
(Epstein et al., 2001). HIF- $\alpha$ proteins are maintained at low steady-state level under normoxic condition via hydroxylation by $\mathrm{HIF}$ Prolyl Hydroxylases (PHDs) (Jaakkola et al., 2001). HIF consists of an unstable $\alpha$ subunit and a stable $\beta$ subunit that binds DNA at specific locations termed Hypoxia Response Elements (HERs) to regulate many genes expressions related to hypoxia (Wiesener et al., 1998). HIF- $\alpha$ subunit is regulatory and unique to the hypoxic response. HIF- $\alpha$ subunit is constitutive and involved in xenobiotic response. Three different genes encoding $\mathrm{HIF}-\alpha$ subunit are found in mammals: HIF-1 $\alpha$ to HIF-3 $\alpha$ (Maxwell, 2005). Among these three $\mathrm{HIF}-\alpha$ isoforms, $\mathrm{HIF}-2 \alpha$ in particular shows a unique ability to induce metabolic reprogramming which ultimately makes mitochondrion harmless but less active in certain conditions by regulating expression of numerous genes (Aragones et al., 2008).

Because n-3 PUFAs showed protective effects on skeletal muscle that shared similar mechanism as myocardium (Peoples and McLennan, 2010; Ayre and Hulebrt, 1996) and a beneficial effect on ischemia and Ischemia/Reperfusion (I/R) injury of tissues by normoxic induction of HIF-2 $\alpha$ (Aragones et al., 2008), we hypothesize that n-3 PUFAs may have an inhibitory effect on PHD1 which is contributed to HIF stabilization and protection of skeletal muscle. We employed $\mathrm{C}_{2} \mathrm{C}_{12}$ murine skeletal myoblasts as a model to determine if these effects are associated with role of prolyl hydroxylase inhibitor and induction of HIF-2 $\alpha$. We used Linoleic Acid (LA; C18:2 n-6)-one of the important n-6 fatty acids as a positive control to compare with the effect of n-3 PUFAs.

\section{MATERIALS AND METHODS}

Dulbecco's Modified Eagle's Medium (DMEM) was purchased from Cellgro (Manassas, VA). Penicillin/ streptomycin, Phosphate-Buffered Saline (PBS), fatty acid-free Bovine Serum Albumin(BSA) and trypsin-EDTA were purchased from Sigma Chemical (St. Louis, MO). LA, ALA, DHA, EPA and SDA (all FAs were with purity $>99 \%$ ) were obtained from Nu-Chek (Elysan, MN). Murine skeletal muscle-derived $\mathrm{C}_{2} \mathrm{C}_{12}$ myoblasts were purchased from American Type Culture Collection (Manassas, VA), No. CRL-1772. Antibodies for PHDland GAPDH were purchased from Bethyl (Montgomery, TX). Antibodies for HIF-2 $\alpha, \operatorname{PPAR} \alpha$ and secondary antibody coupled to Horse Radish Peroxidase (HRP) were purchased from Abcam (Cambridge, MA).

Cell culture: Mouse skeletal muscle cell line, $\mathrm{C}_{2} \mathrm{C}_{12}$ myoblasts were maintained in DMEM containing $4.5 \mathrm{~g} \mathrm{~L}^{-1}$ glucose supplemented with $10 \%$ Fetal Bovine Serum (FBS), $1 \%$ penicillin/streptomycin at $37^{\circ} \mathrm{C}$ under a $5 \% \mathrm{CO}_{2}$ atmosphere in $100 \mathrm{~mm}$ culture dishes or six-well plates. About 2 days after the cells reached confluence, differentiation was induced by switching the growth medium to DMEM supplemented with $2 \%$ horse serum (differentiation medium). The medium was changed every other day. To examine the effect of n-3 PUFAs, after 4 days differentiation, $\mathrm{C}_{2} \mathrm{C}_{12}$ myotubes were treated with $50 \mu \mathrm{M}$ BSA, LA, ALA, DHA, EPA and SDA for $72 \mathrm{~h}$. LA (14.0 mg), ALA (13.9mg), DHA (16.4 mg), EPA (15.1 mg) and SDA $(13.8 \mathrm{mg})$ were dissolved in $1.6 \mathrm{~mL}$ of $0.1 \mathrm{M} \mathrm{KOH}$ $\left(50^{\circ} \mathrm{C}\right.$ for $10 \mathrm{~min}$ ) and incubated with $40 \mathrm{~mL}$ of $1.25 \mathrm{mM}$ fatty acid free bovine serum albumin solution overnight at $4^{\circ} \mathrm{C}$. PBS $1 \mathrm{X}$ was added until the volume of solution reached to $50 \mathrm{~mL}$. Finally, fatty Acid-bovine Serum Albumin (BSA) complex was filter-sterilized using $0.22 \mathrm{~mm}$ filter (Millipore, Billerica, MA) to make $1 \mathrm{mM}$ stock solution ( $\mathrm{pH}$ 7.2). BSA solution without fatty acid was used as a vehicle control. LA was used as a positive control.

Western blot analysis: $\mathrm{C}_{2} \mathrm{C}_{12}$ myotubes were washed with PBS and cell lysates were isolated in RIPA buffer $(50 \mathrm{mM}$ Tris- $\mathrm{HCl}$ ( $\mathrm{pH}$ 7.4), $150 \mathrm{mMNaCl}, 1$ mM EDTA, 1\% Triton $\mathrm{X}-100,1 \%$ Sodium Deoxycholate and $0.1 \%$ SDS) supplemented with protease inhibitors (1 $\mathrm{mM}$ PMSF, $5 \mathrm{mg} \mathrm{mL} \mathrm{m}^{-1}$ aprotinin and $5 \mathrm{mg} \mathrm{mL}^{-1}$ leupeptin) and phosphatase inhibitors ( $1 \mathrm{mM} \mathrm{Na}_{3} \mathrm{VO}_{4}$ and $1 \mathrm{mM} \mathrm{NaF}$ ) and centrifuged at 12,000 r.p.m. for $20 \mathrm{~min}$ at $4^{\circ} \mathrm{C}$. Protein concentration was determined by Bio-Rad protein assay (Hercules, CA) using $1.4 \mathrm{mg} \mathrm{mL}^{-1} \mathrm{BSA}$ as the standard. Proteins $(25 \mu \mathrm{g})$ were separated on SDS-PAGE and transferred to PVDF membranes (Millipore, Billerica, MA). After blocking with a specific primary antiserum in Tris Buffered Saline (TBS) containing $0.05 \%$ Tween-20 (TBS-T) and $5 \%$ non-fat dry milk at $4^{\circ} \mathrm{C}$ overnight, the membrane was incubated with each antibody (anti-PHD1, anti-HIF-2 $\alpha$, anti-PPAR $\alpha$, anti-GAPDH) at $4^{\circ} \mathrm{C}$ overnight. Finally, after three washes with TBS-T, the blots were incubated with secondary antibody coupled to HRP for $1 \mathrm{~h}$ at room temperature, visualized using ECL Plus Western Blotting Detection System (GE Healthcare, Buckin-Ghamshire, UK) and quantified by Kodak Image Station Software (Scion, Frederick, MD).

RNA isolation and one-step reverse transcriptase, realtime-polymerase chain reaction: After treatment, total RNA from $\mathrm{C}_{2} \mathrm{C}_{12}$ myotubes was isolated with Trizol Reagent (Invitrogen, Carlsbad, CA) according to the 
Table 1: Information of gene primers used for RT-PCR

\begin{tabular}{|c|c|c|c|c|}
\hline Gene & Assay ID & Ref_Seq & $\begin{array}{c}\text { Exon } \\
\text { boundary }\end{array}$ & $\begin{array}{l}\text { Assay } \\
\text { location }\end{array}$ \\
\hline Arnt2 & Mm00476004_m1 & - & $12-13$ & 1343 \\
\hline$C p t l b$ & Mm00487200_m1 & NM_009948.2 & $17-18$ & 2228 \\
\hline$E G L N 2$ & Mm00519067_m1 & NM_053208.4 & $2-3$ & 1227 \\
\hline$E P A S I$ & Mm01236112_m1 & NM_010137.3 & 6-7 & 1192 \\
\hline$F A S$ & Mm00662291_g1 & NM_007988.3 & $14-15$ & 2826 \\
\hline GLUT4 & Mm00436615_m1 & NM_009204.2 & $9-10$ & 1328 \\
\hline$H I F-1 \alpha$ & Mm00468869_m1 & NM_010431.2 & $4-5$ & 879 \\
\hline$H I F-3 \alpha$ & Mm00469373_m1 & - & $10-11$ & 1407 \\
\hline$P D K 4$ & Mm01166879_m1 & NM_013743.2 & $3-4$ & 454 \\
\hline$P P A R \alpha$ & Mm00440939_m1 & NM_011144.6 & $7-8$ & 1371 \\
\hline$U C P 2$ & Mm00627597_m1 & NM_011671.4 & $1-2$ & 119 \\
\hline
\end{tabular}

manufacturer's instructions. A one-step was performed in a Veriti ${ }^{\circledR} 96$ well Fast Thermal Cycler (Applied Biosystems, Foster City, CA) to reverse transcribe the mRNA into cDNA which was then amplified using the High Capacity cDNA Reverse Transcription kit (Applied Biosystems, Foster City, CA) and TaqMan Gene Expression Assays (Applied Biosystems, Foster City, CA). All reactions were performed in 96 well plates with a final volume of $20 \mu \mathrm{L}$ per well. Cycling conditions were $2 \mathrm{~min}$ at $50^{\circ} \mathrm{C}$ followed by $10 \mathrm{~min}$ at $95^{\circ} \mathrm{C}$ to activate the HotStarTaq DNA Polymerase, 40 cycles of $15 \mathrm{sec}$ at $94^{\circ} \mathrm{C}$ and $1 \mathrm{~min}$ at $60^{\circ} \mathrm{C}$. TaqMan gene expression assays were obtained from Applied Biosystems (Foster city, CA). The information of gene primers used for amplification is shown in Table 1. Glyceraldehyde-3-Phosphate Dehydrogenase (GAPDH) was amplified and used as a within-sample normalizing control (Assay ID Mm99999915_g1). Data was obtained by the method referred to in former research (Platt and El-Sohemy, 2009).

Statistical analyses: Results were expressed as mean $\pm \mathrm{SE}$ with at least triplication in each group. All differences were analyzed using a one-way Analysis of Variance (ANOVA) followed by Tukey's multiple comparison test. $\mathrm{p}<0.05$ was considered significant. All data was analyzed using SAS Software (Version 9.2, SAS Institute Inc., Cary, $\mathrm{NC}$ ).

\section{RESULTS AND DISCUSSION}

Gene expression of HIFs and PHD1: The effect of n-3 PUFAs on gene expression of three types of HIF- $\alpha$ subunits, HIF- $\beta$ subunit and $\mathrm{HIF}-\alpha$ subunit hydroxylase was determined. There was no significant difference among different gene expression at treatment of $24 \mathrm{~h}$. As shown in Fig. 1a, ALA, EPA and SDA had effect on $H I F-1 \alpha$ gene expression at $72 \mathrm{~h}$. As shown in Fig. $1 \mathrm{~b},>2$ fold increase in EPAS1 $(H I F-2 \alpha)$ gene expression was noted in $\mathrm{C}_{2} \mathrm{C}_{12}$ myotubes in the presence of DHA, EPA and SDA at $72 \mathrm{~h}(\mathrm{p}<0.05) . H I F-3 \alpha$ gene expression was unaltered by all treatments at different time (Fig. 1c). The expression of ARNT2 $(H I F-\alpha)$ gene was significantly elevated by both EPA and SDA relative to CTRL and LA at $72 \mathrm{~h}(\mathrm{p}<0.05)$ (Fig. 1d). Interestingly, DHA, EPA and SDA also increased the expression of EGLN2 (PHD1) gene, compared with CTRL and LA both at 48 and $72 \mathrm{~h}$ $(\mathrm{p}<0.05)$ (Fig. 1e).

Protein expression of HIF-2 $\alpha$ and PHD1: After determining the effect of $n-3$ PUFAs on HIFs and PHD1 in mRNA level, protein expression of $\mathrm{HIF}-2 \alpha$ and PHD1 by $\mathrm{C}_{2} \mathrm{C}_{12}$ myotubes was also determined. As shown in Fig. 2 , no difference of $\mathrm{PHD} 1$ protein was observed in all groups at different time. The effect of DHA, EPA and SDA on increasing $\mathrm{HIF}-2 \alpha$ protein expression was shown at $72 \mathrm{~h}$ in Fig. 2c.

Gene and protein expression of PPAR $\alpha$ pathway: As recently noted (Aragones et al., 2008) enhanced expressions of PDK4 and PPAR $\alpha$ associated with stabilized HIF-2 $\alpha$ were shown in mouse muscle. To determine if the effect of n-3 PUFAs on stabilization of $\mathrm{HIF}-2 \alpha$ might be mediated by $\operatorname{PPAR} \alpha$ pathway, the effects of n-3 PUFAs on PDK4 and PPAR $\alpha$ expression in $\mathrm{C}_{2} \mathrm{C}_{12}$ myotubes were measured. There was no significant difference in both PDK4 and PPAR $\alpha$ gene expression at treatment of $24 \mathrm{~h}$. Compared with CTRL and LA ( $<<0.05)$, a significant elevation of PDK4 gene expression was evident in $\mathrm{C}_{2} \mathrm{C}_{12}$ myotube treated with DHA, EPA and SDA at $72 \mathrm{~h}$ as shown in Fig. 3a. The higher PPAR $\alpha$ gene expression was observed with SDA treatment $(\mathrm{p}<0.05)$ but no difference was observed in other groups relative to CTRL and LA at $72 \mathrm{~h}$ (Fig. 3b). Unlike the PPAR $\alpha$ gene expression, DHA, EPA and SDA increased $\operatorname{PPAR} \alpha$ protein expression in comparison with CTRL and LA at $72 \mathrm{~h}$ (Fig. 3e).

Gene expression of glucose and lipid metabolism enzymes: There was no significant difference among GLUT4, CPT1b and UCP2 gene expression at treatment of $24 \mathrm{~h}$. As a marker for glucose metabolism, GLUT4 gene expression was only increased by SDA compared with CTRL and LA at $72 \mathrm{~h}(\mathrm{p}<0.05)$ (Fig. 4a). For a key enzyme of fatty acid $\beta$-oxidation, CPT1b gene expression was elevated by over 3 fold in the treatment of EPA and SDA at $72 \mathrm{~h}(\mathrm{p}<0.05)$ (Fig. 4b). However, gene expression of FAS was undetermined in all groups at different time. DHA, EPA and SDA significantly increased UCP2 gene 


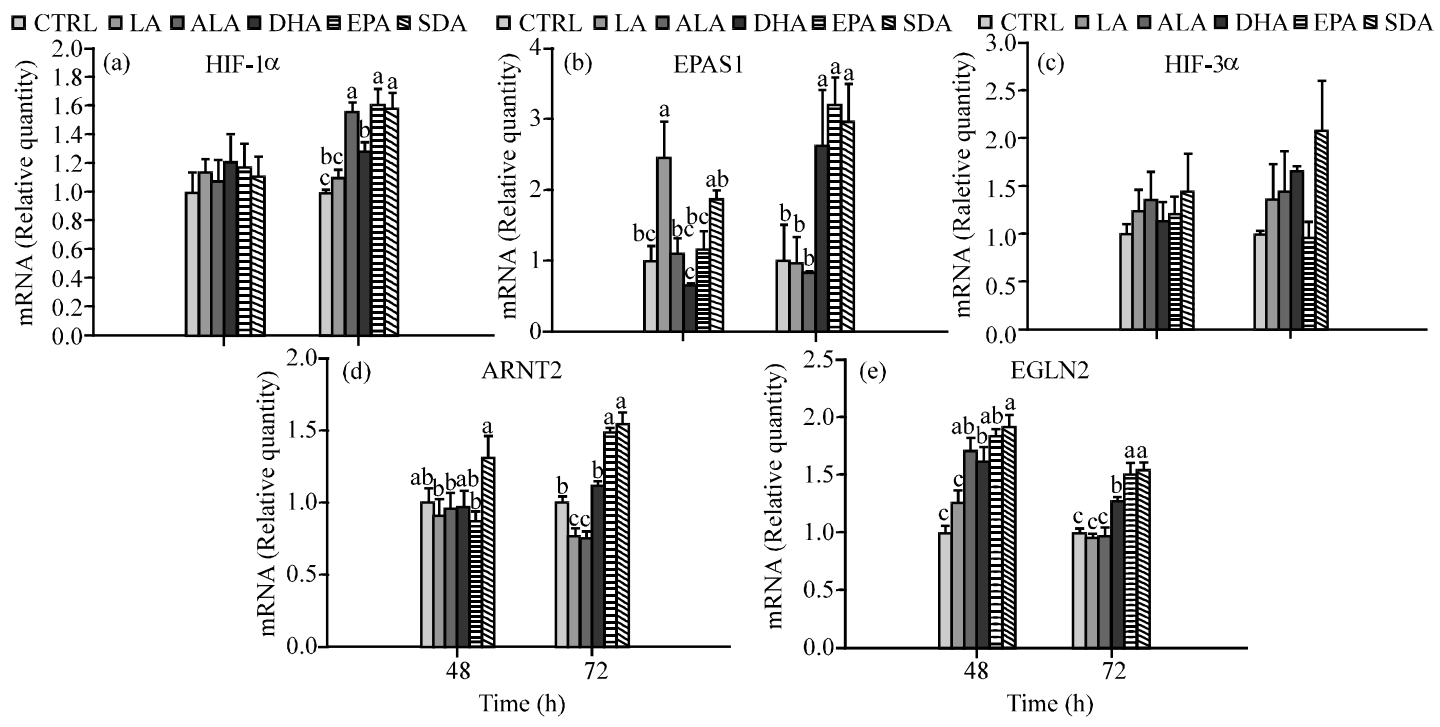

Fig. 1: Effects of individual n-3 PUFAs on gene expression of HIFs and PHD1 in $\mathrm{C}_{2} \mathrm{C}_{12}$ myotubes. Cells were cultured in 6 well plates and treated for 24, 48 and $72 \mathrm{~h}$ in medium with BSA, LA, ALA, DHA, EPA and SDA at concentration of $50 \mu \mathrm{M}$. Values are expressed as mean $\pm \mathrm{SE}(\mathrm{n}=4)$; a) The effect of individual n-3 PUFAs on HIF$1 \alpha$; b) EPAS1 (HIF-2 $\alpha$ ); c) HIF-3 $\alpha$; d) ARNT2 (HIF- $\beta$ ) and e) EGLN2 (PHD1) gene expression was analyzed using one-way ANOVA followed by Tukey's multiple comparison test. Values with different superscript letters are significantly different at $\mathrm{p}<0.05$

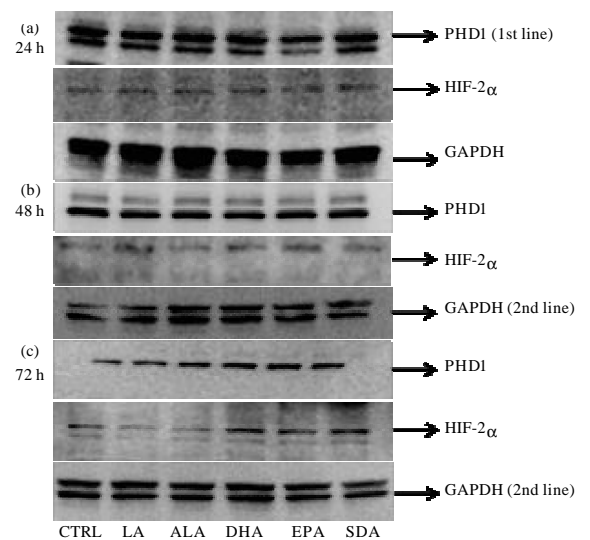

Fig. 2: Effects of individual n-3 PUFAs on protein expression of $\mathrm{PHD} 1$ and $\mathrm{HIF}-2 \alpha$ at a) $24 \mathrm{~h}$, b) $48 \mathrm{~h}$ and c) $72 \mathrm{~h}$ in $\mathrm{C}_{2} \mathrm{C}_{12}$ myotubes. Cells were cultured in $100 \mathrm{~mm}$ dishes and treated for 24,48 and $72 \mathrm{~h}$ in medium with BSA, LA, ALA, DHA, EPA and SDA at concentration of $50 \mu \mathrm{M}$. GAPDH is used as internal control for western blotting analysis

expression $(\mathrm{p}<0.05)$ relative to CTRL and LA at $72 \mathrm{~h}$ (Fig. 4c). In this study, n-3 PUFAs did not show the ability to inhibit PHD1 expression. But interestingly, n-3 PUFAs especially DHA, EPA and SDA, played a role in stabilizing HIF- $2 \alpha$ in the normoxia environment and affected expression of $\mathrm{HIF}$ related transcriptional genes without inhibition of PHD1 at $72 \mathrm{~h}$. This is a new discovery of well-studied n-3 PUFAs on skeletal muscle protective effect. It is suggesting that n-3 PUFAs may induce $\mathrm{HIF}-2 \alpha$ in a PHD1 independent way.

Specifically, n-3 PUFAs species increased HIF- $\alpha$ expression like HIF- $1 \alpha$ and HIF- $2 \alpha$ in mRNA or protein level. The protective effect of HIFs within different tissues has already been noted before (Aragones et al., 2008; Hyvarinen et al., 2010; Natarajan et al., 2006). However, there are some debates about the expression of HIF- $\alpha$ in mRNA and in protein level and also about the constitutive expression of HIF- $\alpha$. Research indicated that there was no significant increase in the mRNA expression of EPAS1 (Forsyth et al., 2008; Westfall et al., 2008). This may be due to posttranscriptional regulation as found in specific cell types (Huang et al., 1998; Lang et al., 2002). In general, HIF- $\alpha$ is constitutively expressed and heterodimerizes with $\mathrm{HIF}-\alpha$ subunit in the nucleus to form a complex which binds to hypoxia-responsive elements in enhancers and promoters of oxygen-responsive genes under hypoxic conditions (Westfall et al., 2008). In contrast to this however, former research (Lang et al., 2002) showed that HIF- $\alpha$ mRNA expression was upregulated under hypoxia. Consistent with this study, the expression of ARNT2 was increased by supplementation of n-3 PUFAs, especially EPA and SDA which may reflect differences in both the methodology and cell lines used. 

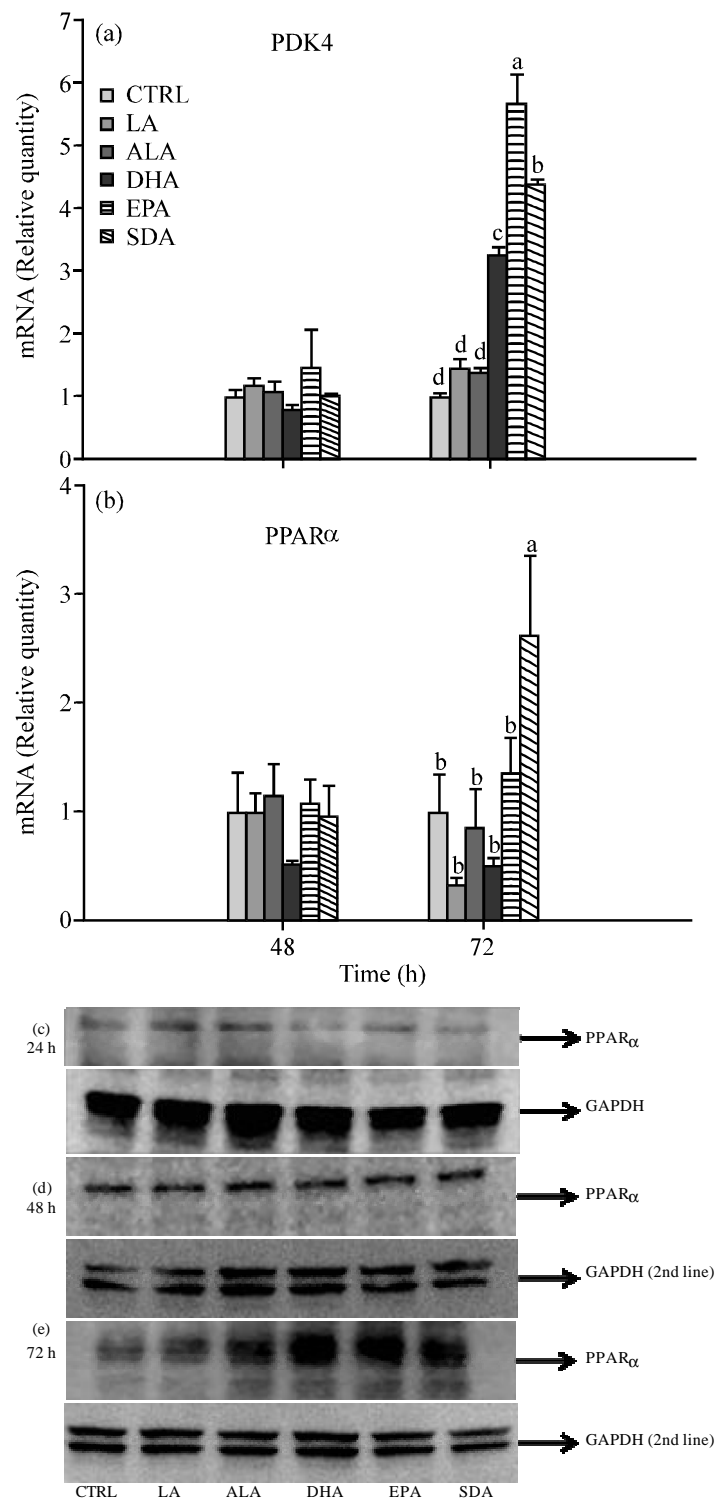

Fig. 3: Effects of individual n-3 PUFAs on gene and protein expression of PPAR $\alpha$ pathway in $\mathrm{C}_{2} \mathrm{C}_{12}$ myotubes. Cells were cultured in six-well plates or $100 \mathrm{~mm}$ dishes and treated for 24,48 and $72 \mathrm{~h}$ in medium with BSA, LA, ALA, DHA, EPA and SDA at concentration of $50 \mu \mathrm{M}$. Values are expressed as mean $\pm \mathrm{SE}(\mathrm{n}=4)$. a) The effect of individual $\mathrm{n}-3$ PUFAs on PDK4; b) PPAR $\alpha$ gene expression was analyzed using one-way ANOVA followed by Tukey's multiple comparison test. Values with different superscript letters are significantly different at $\mathrm{p}<0.05 ; \mathrm{c}$ ) The effect of individual $\mathrm{n}-3$ PUFAs on PPAR $\alpha$ protein expression at different time is shown $24 \mathrm{~h}$, d) 48 and e) $72 \mathrm{~h}$. GAPDH is used as internal control for western blotting analysis
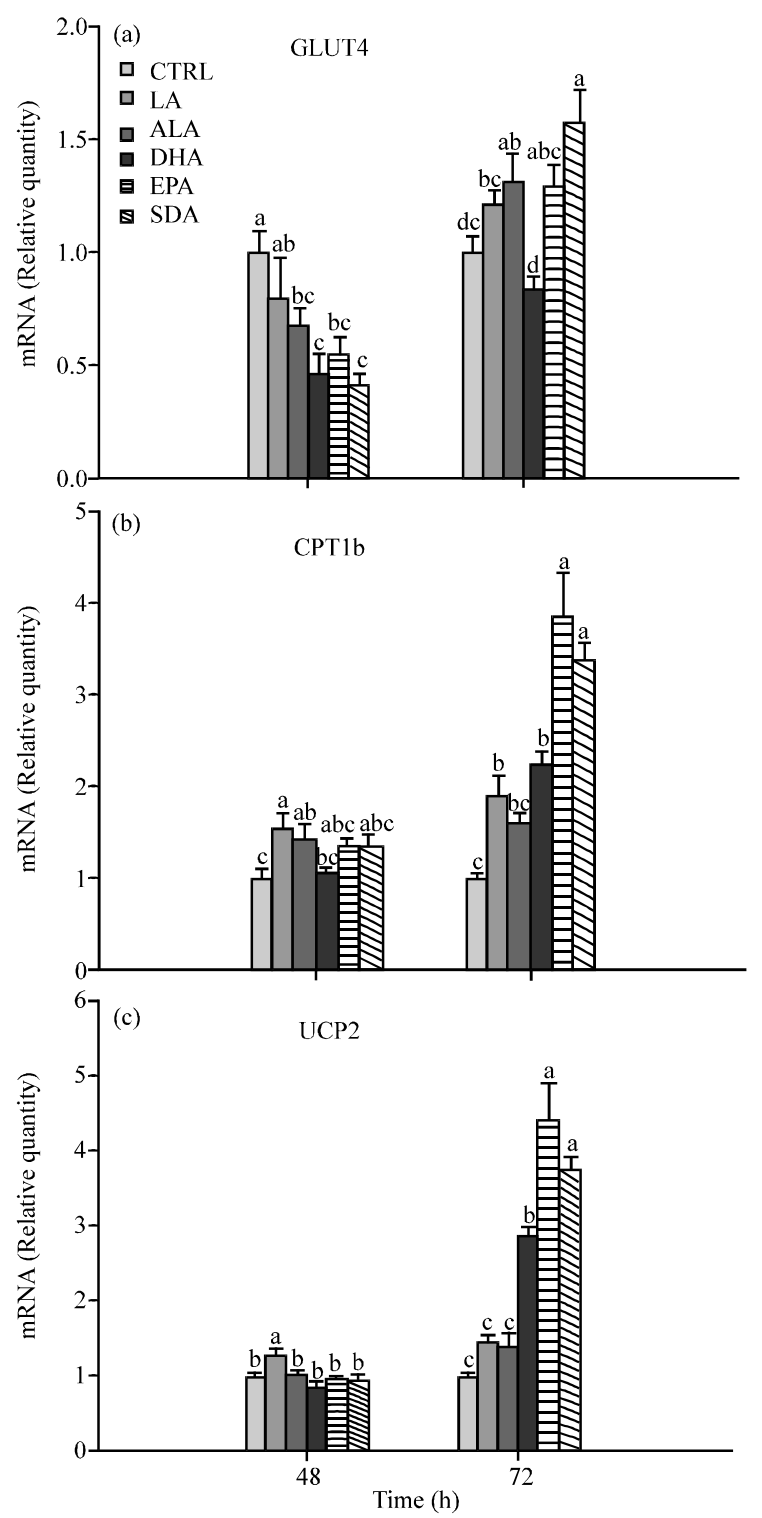

Fig. 4: Effects of individual n-3 PUFAs on gene expression of glucose and lipid metabolism enzymes in $\mathrm{C}_{2} \mathrm{C}_{12}$ myotubes. Cells were cultured in six-well plates and treated for 24,48 and $72 \mathrm{~h}$ in medium with BSA, LA, ALA, DHA, EPA and SDA at concentration of $50 \mu \mathrm{M}$. Values are expressed as mean \pm SE $(n=4)$, a) The effect of individual $n-3$ PUFAs on GLUT4, b) CPT1b and c) UCP2 gene expression was analyzed using one-way ANOVA followed by Tukey's multiple comparison test. Values with different superscript letters are significantly different at $\mathrm{p}<0.05$

The possible mechanism inducing protective effect of $\mathrm{HIFs}$, especially HIF- $2 \alpha$, is linked to an increase in the 
expression of PDK4 (Kelly, 2008). In the normoxic environment, pyruvate enters the Tricarboxylic Acid (TCA) Cycle inside the mitochondrion where it generates ATP in the presence of oxygen. But in the hypoxia environment like heart ischemia, entry of pyruvate is restricted by expression of $\mathrm{PDK} 4$ which is associated with induction of HIF-2 $\alpha$ (Aragones et al., 2008; Wu et al., 2001). In this study, $P D K 4$ gene expression was upregulated in myotubes treated DHA, EPA and SDA.

PPAR $\alpha$ is known to activate the PDK4 gene (Wu et al., 2001). Research on the hibernating mammal model also showed the level of PDK 4 mRNA increased greatly by activation of $\operatorname{PPAR} \alpha$ during hibernation (Buck et al., 2002). Hearts from PPAR $\alpha$ agonist clofibratetreated rats had an improved recovery of post-ischemic contractile function and reduced Ischemia/Reperfusion (I/R)-induced infarct size. In hearts of rats the content of the principal n-3 PUFA (DHA) was markedly increased while the principal n-6 PUFA (LA) and n-6/n-3 ratio was significantly reduced (Tian et al., 2006). In this study, we found that DHA, EPA and SDA significantly increased $\operatorname{PPAR} \alpha$ protein expression. This result, combined with $P D K 4$ gene expression and HIF- $2 \alpha$ expression, suggests that PPAR $\alpha$ activated by $n-3$ PUFAs with induction of $\mathrm{HIF}-2 \alpha$ can initiate $P D K 4$ gene expression and this process implies a reprogramming of basal metabolism in cells, especially in energy production and utilization like glucose metabolism and fatty acid metabolism. Glycolytic flux was increased in mouse muscle fiber in low oxygen conditions (Argarones et al., 2008). As a maker for glucose metabolism, SDA increased GLUT4 gene expression significantly in this study. Combined, n-3 PUFAs may induce more glucose entering cell cytoplasm to generate ATP by glycolysis when HIF-2 $\alpha$ was induced. CPT1b is known as a rate-limiting enzyme in fatty acid $\alpha$-oxidation which transfers fatty acids through mitochondrial membrane to be oxidized within the mitochondrial matrix (McGarry and Brown, 1997). In vivo experiment, rats fed with fish oil had a significantly greater skeletal muscle CPT1 specific activity (Power and Newsholme, 1997). Consistent with this study, both EPA and SDA significantly elevated CPT1b gene expression. In another in vivo experiment, dietary fish oil reduced skeletal muscle oxygen consumption in hindlimbs of rats (Peoples and McLennan, 2010). Along with this study, fatty acids became the primary source of fuel in hibernating mammals, who consumed less oxygen for energy production because of the inhibition of carbohydrate oxidation by the enzyme PDK4 (Buck et al., 2002). Former research and this study suggest that n-3 PUFAs could switch the energy source from carbohydrate to fatty acid by the activation of $P D K 4$ gene in $\operatorname{PPAR} \alpha$ pathway to enable $\mathrm{C}_{2} \mathrm{C}_{12}$ myotubes to consume oxygen more efficiently.

As an important energy expenditure parameter, the effect of Uncoupling Proteins (UCPs) has become prominent in the field of thermogenesis, especially UCP1 (Brand and Esteves, 2005). But for UCP 2 and UCP3, there is a consensus that the primary function of UCP2 and UCP3 is to attenuate mitochondrial production of free radical to protect against oxidative damage, degenerative disease and aging rather than to promote gross thermogenesis or energetic inefficiency (Brand et al., 2002; Casteilla et al., 2001). Oxidative damage caused by Reactive Oxygen Species (ROS) is produced in mitochondrion which can trigger the toxic effects living with oxygen. In contrast, oxygen depletion (hypoxia) also increases mitochondrial ROS that is detrimental to cells unless attenuated (Guzy and Schumacker, 2006). In this study, the UCP2 gene expression in DHA, EPA and SDA treatment was elevated greatly which is consistent with former research done on effect of elucidating UCP2 on attenuating ROS production (Arsenijevic et al., 2000; Cortez-Pinto et al., 2001).

\section{CONCLUSION}

To the knowledge this study is the first to examine the effect of n-3 PUFAs on induction of HIF- $2 \alpha$ in $\mathrm{C}_{2} \mathrm{C}_{12}$ myotubes. Interestingly, this induction is not associated with inhibition of PHD1 which could be associated with other PHDs. Several lines of evidence suggest the protective effect of n-3 PUFAs on induction of HIF- $2 \alpha$ plays a part by upregulation of $P D K 4$ gene expression which is activated by $\operatorname{PPAR} \alpha$. This process can imply a reprogramming of basal metabolism in $\mathrm{C}_{2} \mathrm{C}_{12}$ myotubes to consume oxygen more efficiently by switching carbohydrate oxidation to glycolysis and fatty acid oxidation. Meanwhile, n-3 PUFAs also increased UCP2 gene expression to attenuate the damage of ROS. This study provides a new interpretation of protective effect in skeletal muscle and myocardium by n-3 PUFAs, especially DHA, EPA and SDA.

\section{NOMENCLATURE}

$\begin{aligned} \text { ALA }= & \text { Alpha Linolenic Acid } \\ \text { ARNT2 }= & \text { Aryl hydrocarbon Receptor Nuclear } \\ & \text { Translocator } 2 \\ \text { CPT1b }= & \text { Carnitine Palmitoyltransferase 1b } \\ \text { DHA }= & \text { Docosahexaenoic Acid } \\ \text { EGLN2 }= & \text { Eg1 Nine homolog } 2 \\ \text { EPA }= & \text { Eicosapentaenoic Acid }\end{aligned}$




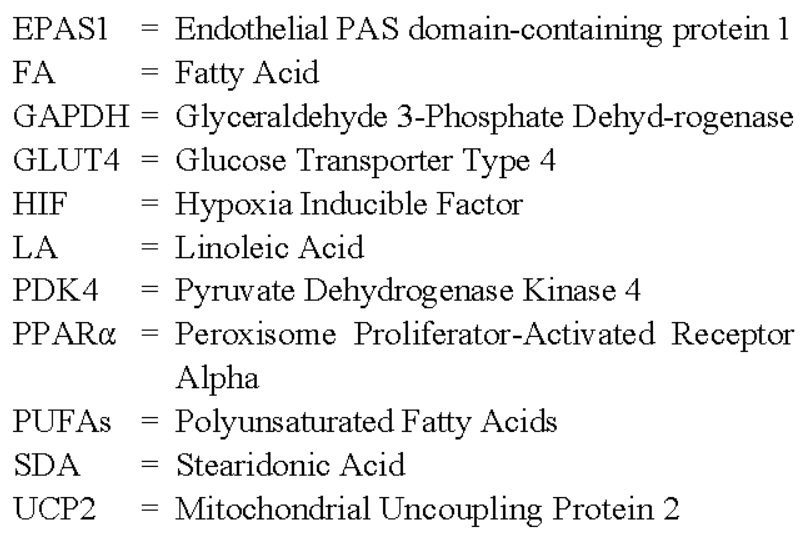

\section{ACKNOWLEDGEMENT}

Researcher grateful all the help from National key Laboratory of Animal Nutrition and Department of Food Science, University of Massachusetts Amherst.

\section{REFERENCES}

Anand, V., Chenniappan, Kalavathy, Uma, Saravanan and S. Kumar, 2008. Redeeming measure of atorvastatin in the risk factors of cardiovascular disease. Int. J. Pharmacol., 4: 305-309.

Ara, N., M. Rashid and M.S. Amran, 2008. Comparison of hypotensive and hypolipidemic effects of Catharanthus roseus leaves extract with nifedipine on adrenaline induced hypertensive rats. J. Boil. Sci., 8: 1082-1086.

Aragones, J., M. Schneider, K. Van Geyte, P. Fraisl and T. Dresselaers et al., 2008. Deficiency or inhibition of oxygen sensor Phdl induces hypoxia tolerance by reprogramming basal metabolism. Nature Genet., 40: 170-180.

Arsenijevic, D., H. Onuma, C. Pecqueur, S. Raimbault and B.S. Manning et al., 2000. Disruption of the uncoupling protein- 2 gene in mice reveals a role in immunity and reactive oxygen species production. Nat. Genet., 26: 435-439.

Ayre, K.J. and A.J. Hulebrt, 1996. Dietary fattyacid profile influences the composition of skeletal muscle phospholipids in rats. J. Nutr., 126: 653-662.

Bernhardt, W.M., C. Warnecke, C. Willam, T. Tanaka, M.S. Wiesener and K.U. Eckardt, 2007. Organ protection by hypoxia and Hypoxia-inducible factors. Methods Enzymol., 435: 221-245.

Brand, M.D. and T.C. Esteves, 2005. Physiological functions of the mitochondrial uncoupling proteins UCP2 and UCP3. Cell Metab., 2: 85-93.
Brand, M.D., R. Pamplona, M. Portero-Otin, J.R. Requena and S.J. Roebuck et al., 2002. Oxidative damage and phospholipid fatty acyl composition in skeletal muscle mitochondria from mice underexpressing or overexpressing uncoupling protein 3. Biochem. J., 368: 597-603.

Buck, M.J., T.L. Squire and M.T. Andrews, 2002. Coordinate expression of the PDK4 gene: A means of regulating fuel selection in a hibernating mammal. Physiol. Genomics, 8: 5-13.

Casteilla, L., M. Rigoulet and L. Penicaud, 2001. Mitochondrial ROS metabolism: Modulation by uncoupling proteins. IUBMB Life, 52: 181-188.

Cortez-Pinto, H., H.Z. Lin, S.Q. Yang, S.O. da Costa and A.M. Diehl, 2001. Lipids up-regulate uncoupling protein 2 expression in rat hepatocytes. Gastroenterology, 116: 1184-1193.

De Lorgeril, M., S. Renaud, N. Mamelle, P. Salen and J.L. Martin et al., 1994. Mediterranean á-linolenic acid-rich diet in secondary prevention of coronary heart disease. Lancet, 343: 1454-1459.

Epstein, A.C., J.M. Gleadle, L.A. McNeill, K.S. Hewitson and J. O'Rourke et al., 2001. Elegans EGL-9 and mammalian homologs define a family of dioxygenases that regulate HIF by prolyl hydroxylation. Cell, 107: 43-54.

Fang, Y., J. Favre, M. Vercauteren, B. Laillet and I. Remy-Jouet et al., 2011. Reduced cardiac remodelling and prevention of glutathione deficiency after omega-3 supplementation in chronic heart failure. Fundamental Clin. Pharmacol., 25: 323-332.

Forsyth, N.R., A. Kay, K. Hampson, A. Downing, R. Talbot and J. McWhir, 2008. Transcriptome alterations due to physiological normoxic $\left(2 \% \mathrm{O}_{2}\right)$ culture of human embryonic stem cells. Regenerative Med., 3: 817-833.

Granzotto, M., Z. Cristina, D. Ilenia, B. Fiora and D. Giuliana, 2005. Modulation of MDR1 gene expression by a chronic treatment with verapamil in caco-2 cells. Int. J. Pharmacol., 1: 85-92.

Guzy, R.D. and P.T. Schumacker, 2006. Oxygen sensing by mitochondria at complex III: The paradox of increased reactive oxygen species during hypoxia. Exp. Physiol., 91: 807-819.

Huang, L.E., J. Gu, M. Schau and H.F. Bunn, 1998. Regulation of hypoxia-inducible factor 1alpha is mediated by an O2-dependent degradation domain via the ubiquitin-proteasome pathway. Proc. National Acad. Sci. U.S.A., 95: 7987-7992. 
Hyvarinen, J., I.E. Hassinen, R. Sormunen, J.M. Maki, K.I. Kivirikko, P. Koivunen and J. Myllyharju, 2010. Hearts of hypoxia-inducible factor prolyl 4hydroxylase- 2 hypomorphic mice show protection against acute ischemia-reperfusion injury. J. Biol. Chem., 10.1074/jbc.M109.084855.

Jaakkola, P., D.R. Mole, Y.M. Tian, M.I. Wilson and J. Gielbert et al., 2001. Targeting of HIF-alpha to the Von Hippel Lindau ubiquitylation complex by $\mathrm{O}_{2}-$ regulated prolyl hydroxylation. Science, 292: 468-472.

Jalali-Khanabadi, B.A., H. Mozaffari-Khosravi, M. Rafiei, S.M. Ghoreishian and F. Darabi, 2006. Association of cholesterol-rich lipoproteins with coronary artery disease in subjects who referred to yazd cardiovascular research center for coronary angiography. Pak. J. Biol. Sci., 9: 2777-2780.

Joensen, A.M., E.B. Schmidt, C. Dethlefsen, S.P. Johnsen, A. Tjonneland, L.H. Rasmussen and K. Overvad, 2010. Dietary intake of total marine n-3 polyunsaturated fatty acids, eicosapentaenoic acid, docosahexaenoic acid and docosapentaenoic acid and the risk of acute coronary syndrome: A cohort study. Br. J. Nutr., 103: 602-607.

Jun, T., Z. Liancai and W. Bochu, 2007. Effect of ginsenosides on malondialdehyde, nitric oxide and endothelin-1 production in vascular endothelial cells suffering from lipid peroxidation injury. Int. J. Pharmacol., 3: 101-105.

Kelly, D., 2008. Hypoxic reprogramming. Nat. Genet., 40: 132-134.

Kris-Etherton, P.M., W.S. Harris and L.J. Appel, 2002. Fish consumption, fish oil, omega-3 fatty acids and cardiovascular disease. Circulation, 106: 2747-2757.

Lang, K.J., A. Kappel and G.J. Goodall, 2002. Hypoxiainducible factor-1alpha mRNA contains an internal ribosome entry site that allows efficient translation during normoxia and hypoxia. Mol. Biol. Cell, 13: 1792-1801.

Liu, C., R. Dai, R. Yu and J. Xu, 2011. Morphine preconditioning, cardioprotection and left ventricular remodelling in rabbits. Acta Cardiologica, 66: 341-348.

Lorgeril de M. and P. Salen, 2004. Alpha-linolenic acid and coronary heart disease. Nutr. Metab. Cardiovasc Dis., 14: 162-169.

Maxwell, P.H., 2005. Hypoxia-inducible factor as a physiological regulator. Exp. Physiol., 90: 791-797.

Mazloom, Z., M. Salehi and M.H. Eftekhari, 2008. Blood lipid and lipoprotein profile of female athletes with respect to their jobs and nutrients intake. Pak. J. Biol. Sci., 11: 142-144.

McGarry, J.D. and N.F. Brown, 1997. The mitochondrial carnitine palmitoyltransferase system from concept to molecular analysis. Eur. J. Biochem., 244: 1-14.
$\mathrm{Mu}, \mathrm{H} ., 2$ 2008. Bioavailability of omega-3 long-chain polyunsaturated fatty acids from foods. Agro. Food Ind. Hi-Tech., 19: 24-26.

Natarajan, R., F.N. Salloum, B.J. Fisher, R.C. Kukreja and A.A. Fowler, 2006. Hypoxia inducible factor-1 activation by prolyl 4-hydroxylase-2 gene silencing attenuates myocardial ischemia reperfusion injury. Circulation Res., 98: 133-140.

Nishimura, M., C. Sakoda, M. Murakawa, Y. Okamoto and T. Tokoro et al., 2011. Oral Nicorandil for prevention of cardiac death in hemodialysis patients without obstructive coronary artery disease: A propensitymatched patient analysis. Nephron. Clin. Pract., 119: c301-c309.

Ogita, H., K. Node, H. Asanuma, S. Sanada and S. Takashima et al., 2003. Eicosapentaenoic acid reduces myocardial injury induced by ischemia and reperfusion in rabbit hearts. J. Cardiovasc. Pharmacol., 41: 964-969.

Peoples, G.E. and P.L. McLennan, 2010. Dietary fish oil reduces skeletal muscle oxygen consumption, provides fatigue resistance and improves contractile recovery in the rat in vivo hindlimb. Br. J. Nutr., 104: 1771-1779.

Pepe, S. and P.L. McLennan, 2002. Cardiac membrane fatty acid composition modulates myocardial oxygen consumption and postischemic recovery of contractile function. Circulation, 105: 2303-2308.

Platt, I.D. and A. El-Sohemy, 2009. Regulation of osteoblast and adipocyte differentiation from human mesenchymal stem cells by conjugated linoleic acid. J. Nutr. Biochem., 20: 956-964.

Power, G.W. and E.A. Newsholme, 1997. Dietary fatty acids influence the activity and metabolic control of mitochondrial carnitine palmitoyltransferase $\mathrm{I}$ in rat heart and skeletal muscle. J. Nutr., 127: 2142-2150.

Ruiz-Lopez, N., R.P. Haslam, M. Venegas-Calerpon, T.R. Larson, I.A. Graham, J.A. Napier and $O$. Sayanova, 2009. The synthesis and accumulation of stearidonic acid in transgenic plants: A novel source of heart-healthy omega-3 fatty acids. Plant Biotechnol. J., 7: 704-716.

Shekhar, H.U., H.M. Shahjalal, R. Ahmed, M. Uddin and Kaniz-Khatun-E-Jannath, 2006. Prevalence of dyslipidemic phenotypes including hyper-apoB and evaluation of cardiovascular disease risk in normocholesterolemic type 2 diabetic patients. Pak. J. Biol. Sci., 9: 1536-1541. 
Singh, T.U., K. Kathirvel, S. Choudhury, S.K. Garg and S.K. Mishra, 2010. Eicosapentaenoic acid-induced endothelium-dependent and-independent relaxation of sheep pulmonary artery. Eur. J. Pharmacol., 636: 108-113.

Tian, Q., F.A. Grzemski, S. Panagiotopoulos and J.T. Ahokas, 2006. Peroxisome proliferator-activated receptor alpha agonist, clofibrate, has profound influence on myocardial fatty acid composition. Chemico-Biol. Interact., 160: 241-251.

Vannice, G.K. and J. Kelly, 2004. Fish oil supplementation in people with diabetes: A review of the research. J. Applied Nutr., 54: 81-83.

Westfall, S.D., S. Sachdev, P. Das, L.B. Hearne, M. Hannink, R.M. Roberts and T. Ezashi, 2008. Identification of oxygen-sensitive transcriptional programs in human embryonic stem cells. Stem Cells Develop., 17: 869-882.
Wiesener, M.S., H. Turley, W.E. Allen, C. Willam and K.U. Eckardt et al., 1998. Induction of endothelial PAS domain protein-1 by hypoxia: Characterization and comparison with hypoxia-inducible factor1alpha. Blood, 92: 2260-2268.

Wu, P., J.M. Peters and R.A. Harris, 2001. Adaptive increase in pyruvate dehydrogenase kinase 4 during starvation is mediated by peroxisome proliferatoractivated receptor $\alpha$. Biochem. Biophys. Res. Commun., 287: 391-396.

Xiao, Y.F., D.C. Sigg, M.R. Ujhelyi, J.J. Wilhelm, E.S. Richardson and P.A. Iaizzo, 2008. Pericardial delivery of omega-3 fatty acid: A novel approach to reducing myocardial infarct sizes and arrhythmias. Am. J. Physiol. Heart Circulatory Physiol., 294: H2212-H2218.

Xu, J., K.D. Kochanek, S.L. Murphy and B. Tejada-Vera, 2010. National vital statistics reports. National Center Health Stat., 58: 1-135. 